\title{
Adesão ao uso do ácido fólico em crianças com doença falciforme diagnosticadas na triagem neonatal: fatores associados.
}

Adlherence to folic acid supplementation among children with sickle cell disease diagnosed through

the newborn screening program: associated factors.

Adherencia a la suplementación de ácido fólico en niños com diagnóstico en programa de cribado

neonatal: factores associados.

Recebido: 04/02/2022 | Revisado: 10/02/2022 | Aceito: 17/02/2022 | Publicado: 26/02/2022

\author{
Maria Isabel Silva Soares \\ ORCID: https://orcid.org/0000-0002-1219-3722 \\ Universidades do Estado da Bahia, Brasil \\ E-mail: misoaresfarmacia@gmail.com \\ Yasmin Mazzafera \\ ORCID: https://orcid.org/0000-0003-2239-674X \\ Escola Bahiana de Medicina e Saúde Pública, Brasil \\ E-mail: yasminmazzafera@gmail.com \\ Tatiana Régia Suzana Amorim Boa Sorte \\ ORCID: https://orcid.org/0000-0002-0371-9104 \\ Associação de Pais e Amigos dos Excepcionais de Salvador, Brasil \\ E-mail: tatiana.amorim@ apaesalvador.org.br \\ Gildásio Carvalho da Conceição \\ ORCID: https://orcid.org/0000-0001-7302-8838 \\ Associação de Pais e Amigos dos Excepcionais de Salvador, Brasil \\ E-mail: gildasio.carvalho@ apaesalvador.org.br \\ Ney Cristian Amaral Boa Sorte \\ ORCID: http://orcid.org/0000-0001-7068-3319 \\ Universidade do Estado da Bahia, Brasil \\ E-mail: nboasorte@uneb.br
}

\begin{abstract}
Resumo
Introdução: $\mathrm{O}$ ácido fólico é utilizado como terapia profilática na anemia hemolítica, e sua baixa adesão em crianças com doença falciforme contribui para o surgimento de complicações e piora do estado de saúde e, consequentemente, aumento dos custos assistenciais. Objetivo: Analisar a adesão à farmacoterapia com ácido fólico em crianças com hemoglobinopatia SS (HbSS) ou SC (HbSC), diagnosticadas na triagem neonatal. Método: Estudo transversal, com dosagens de níveis séricos de folato e aplicação dos Teste de Morisky-Green (TMG) e Brief Medication Questionnaire (BMQ) aos cuidadores. Resultados: Verificaram-se $34,0 \%$ e 40,4\% de "aderentes", respectivamente, para TMG e BMQ. Constatou-se folato sérico elevado em 78,7\% dos participantes, e nenhum deles apresentou deficiência. Forma farmacêutica $(\mathrm{p}=0,719)$, faixa etária $(\mathrm{p}=0,875)$, renda $(\mathrm{p}=0,944)$ e escolaridade do cuidador $(\mathrm{p}=0,070)$ não foram fatores associados à adesão. Pacientes HbSS registram mais que o quádruplo da adesão dos $\mathrm{HbSC}$ (48,3\% vs. 11,1\%; $\mathrm{p}=0,012$ ). Dificuldade de acesso ao medicamento e interrupção/atraso no tratamento foram os maiores contribuintes à não adesão. Conclusões: Observou-se contraste entre a adesão referida pelos questionários e os níveis séricos elevados de ácido fólico e a necessidade de melhoria do acesso ao medicamento.
\end{abstract}

Palavras-chave: Anemia Falciforme; Doença da Hemoglobina SC; Ácido Fólico; Adesão ao medicamento.

\begin{abstract}
Introduction: Folic acid is used as a prophylactic therapy in haemolytic anaemia. Low adherence to folic acid in children with sickle cell disease contributes to the emergence of complications and worsening of health, and thus an increase in care costs. Objective: To analyse medication adherence to folic acid in children with sickle cell disease, haemoglobin SS (HbSS) or SC (HbSC), diagnosed by neonatal screening. Methods: Cross-sectional study, by measurements of serum folate levels in children and application of the Morisky-Green Test (MGT) and Brief Medication Questionnaire (BMQ) to caregivers. Results: There were $34.0 \%$ and $40.4 \%$ of "adherents" for MGT and BMQ. Elevated serum folate was found in $78.7 \%$ of the participants, and none of them had deficiency. Pharmaceutical form $(\mathrm{p}=0.719)$, age group $(\mathrm{p}=0.875)$, income $(\mathrm{p}=0.944)$ and caregiver's education $(\mathrm{p}=0.070)$ were not associated factors to adherence. HbSS patients record more than four times the adherence of $\mathrm{HbSC}(48.3 \%$ vs. $11.1 \%$; $\mathrm{p}=0.012)$. Difficulty of access to the medication and interruption/lagging of treatment were the main contributors to non-
\end{abstract}


adherence. Conclusion: There was a contrast between the adherence reported by the questionnaires and the high serum folate levels.

Keywords: Anemia, Sickle Cell; Hemoglobin SC; Folic Acid; Medication Adherence.

\section{Resumen}

Introducción: El ácido fólico se utiliza como terapia profiláctica en la anemia hemolítica. La baja adherencia al ácido fólico en niños con enfermedad de células falciformes contribuye a la aparición de complicaciones y empeoramiento de la salud, y por ende, al aumento de los costos de atención. Objetivos: Analizar la adherencia a la medicación con ácido fólico en niños drepanocíticos SS (HbSS) o SC ( HbSC), diagnosticados mediante cribado neonatal. Métodos: Estudio transversal, con medidas de folato sérico en niños, y cuestionarios Morisky-Green Test (TMG) y Brief Medication Questionnaire (BMQ), aplicados a cuidadores. Resultados: Hubo 34,0\% y 40,4\% de "adherentes" a TMG y BMQ. El 78,7\% de los participantes tenía folato sérico elevado y ninguno de ellos tenía deficiencia. La forma farmacéutica $(p=0,719)$, la edad $(p=0,875)$, la renta familiar $(p=0,944)$ y la educación del cuidador $(p=0,070)$ no fueron factores asociados con la adherencia. Los pacientes con HbSS tuvieron una adherencia en comparación con HbSC más del cuádruple (48,3\% frente a 11,1\%; p =0,012). La dificultad de acceso y la interrupción/retraso del tratamiento fueron los principales factores de no adherencia. Conclusión: Hubo un contraste entre la adherencia reportada por los cuestionarios y los altos niveles de folato sérico.

Palabras clave: Anemia de células falciformes; Enfermedad de la hemoglobina SC; Ácido fólico; Cumplimiento de la medicácion.

\section{Introdução}

Doença Falciforme (DF) compreende um grupo de alterações genéticas caracterizadas pela mutação do gene que codifica a cadeia $\beta$ da hemoglobina ( $\beta$ globina), resultando na produção de uma hemoglobina estruturalmente anormal denominada hemoglobina $\mathrm{S}(\mathrm{HbS})$. Genotipicamente, essa hemoglobinopatia pode ocorrer com a presença da mutação para HbS em homozigose, denominada anemia falciforme (SS), ou associada, em heterozigose, a uma mutação responsável pela ocorrência de outra hemoglobina variante anômala (SC, SD), ou ainda em interação com mutações causadoras de talassemias $(\mathrm{S} \alpha, \mathrm{S} \beta$ o, $\mathrm{S} \beta+)$ (Ware et al.,2017).

A DF representa uma das doenças hematológicas hereditárias de mais elevada frequência mundial, configurando-se como importante problema de saúde pública no Brasil, em função de suas manifestações clínicas e morbimortalidade (Cançado \& Jesus, 2007; Caldas et al., 2010; Piel et al., 2013). Sua incidência média, no país, é de 1 caso a cada 1000 nascidos vivos, sendo a Bahia o estado de maior ocorrência da doença, com estimativas de um afetado a cada 650 casos (Cançado \& Jesus, 2007; Amorim et al., 2010). Desde 2001, por meio da portaria $n^{\circ}$ 822/01, as hemoglobinopatias foram incluídas no Programa Nacional de Triagem Neonatal (PNTN). Essa ação de saúde pública, por meio da assistência multidisciplinar, pôde promover o tratamento precoce com consequente aumento da sobrevida dos afetados e melhoria da sua qualidade de vida (Bandeira et al., 2007).

A abordagem terapêutica multidisciplinar envolve, dentre outros, cuidados médicos, farmacêuticos, nutricionais, psicoterápicos, de enfermagem e de odontologia (Ware et al.,2017). O tratamento farmacológico primário consiste na prescrição de medicamentos para o controle da dor e/ou febre, antibioticoprofilaxia (normalmente realizada com penicilina), imunização (pneumococos, meningococos, influenza, varicela e hepatite A) e terapia profilática diária com ácido fólico (AF) (Braga, 2007; Brasil, 2012). A suplementação de AF nas anemias hemolíticas justifica-se pelo aumento da eritropoiese, considerando, nessas condições, a reduzida meia vida dos eritrócitos (Braga, 2007; Dixit et al., 2018).

Por tratar-se de uma condição crônica, a maioria dos afetados pela DF, especialmente na infância, necessita fazer uso de ao menos um medicamento, por um longo período (Steiner et al., 2013; Walsh et al., 2014). Tal aspecto, somado a outros fatores, favorecem diretamente a má adesão ao tratamento preconizado (Steiner et al., 2013). Adesão é um termo que define a extensão na qual o comportamento de uma pessoa - usar medicamentos, seguir uma dieta e/ou executar mudanças no estilo de vida, corresponde às recomendações acordadas com o profissional de saúde (Obreli-Neto et al., 2012).

A adesão à farmacoterapia pode ser avaliada a partir de métodos objetivos ou subjetivos, diretos ou indiretos, tais 
como detecção do fármaco ou metabólito em fluidos biológicos (dosagem sérica ou urinária); contagem das unidades de medicamentos, diários do paciente, registro de dispensação pela farmácia, registros em prontuários, dispositivos eletrônicos para monitoramento de tomadas do medicamento (Medication Event Monitoring System - MEMS), e questionários ou entrevistas estruturadas (Ben, 2011; Obreli-Neto et al., 2012).

A baixa adesão impacta negativamente no curso e sucesso do tratamento, contribuindo para redução da eficácia dos medicamentos, complicações ou agravamentos das enfermidades, e assim, aumento dos custos de assistência à saúde (Steiner et al., 2013; Walsh et al., 2014). Estudos realizados em crianças brasileiras que tenham avaliado adesão à farmacoterapia entre o público infantil diagnosticado com DF são escassos (Bitarães et al., 2008). Em especial, trabalhos que avaliaram a adesão ao ácido fólico e com avaliação dos níveis séricos deste analito não foram encontrados no Brasil, e são raros ao nível mundial (Azzam et al., 2019; Patel et al., 2010).

Diante disso, este estudo objetivou analisar a adesão ao tratamento profilático com ácido fólico, a partir de resultados laboratoriais dos níveis séricos de ácido fólico, aplicação de questionários específicos de avaliação de adesão junto aos responsáveis das crianças com DF diagnosticadas por triagem neonatal, e acompanhadas regularmente em Serviço de Referência em Triagem Neonatal (SRTN) e uso de dados secundários de prontuários.

\section{Metodologia}

Estudo de corte transversal com 47 pacientes pediátricos atendidos, pelo Sistema Único de Saúde (SUS), em caráter ambulatorial, no SRTN do estado da Bahia, a Associação de Pais e Amigos dos Excepcionais de Salvador (Apae Salvador). Foram incluídas crianças com idade entre 2 e 11 anos, atendidas entre março e outubro de 2019, com diagnóstico de hemoglobinopatia SS ou SC, em uso de ácido fólico profilático, que possuíam resultados de exames laboratoriais em prontuário eletrônico, e cujo responsável legal e/ou participante, após leitura e assinatura de Termo de Consentimento Livre e Esclarecido (TCLE) e/ou Termos de Assentimento Livre e Esclarecido (TALE), respondeu os instrumentos de adesão. Foi adotado como critério de exclusão alguma limitação dos cuidadores que impossibilitasse responder ao questionário ou ausência do responsável pelo tratamento no momento da aplicação dos instrumentos.

Para a avaliação da adesão à terapia com ácido fólico prescrita foram utilizadas as versões validadas em português do Teste de Morisky-Green (TMG) e do Brief Medication Questionnaire (BMQ) (Beckman Coulter Inc., 2005). O TMG consiste em 4 perguntas objetivas, com respostas "SIM' ou "NÃO", equivalendo respectivamente a 0 e 1 ponto. A soma desse escore, permite a classificação em baixa adesão ( 0 a 1 ponto), moderada adesão ( 2 a 3 pontos) ou aderente ( 4 pontos). O BMQ é um instrumento composto por três domínios que permite identificar barreiras à adesão, considerando regime de tratamento medicamentoso prescrito, crenças e recordação em relação à farmacoterapia, sob a perspectiva do paciente. Este último questionário permite a avaliação da adesão ao tratamento considerando os últimos sete dias precedentes à entrevista, classificando os participantes em aderente (nenhuma resposta positiva); provável aderência (resposta positiva em 1 domínio); provável baixa adesão (resposta positiva em 2 domínios); e baixa adesão (resposta positiva em 3 domínios) (Ben, 2011; Bem et al., 2012). Ambos questionários foram aplicados a todos os participantes do estudo.

Para o presente estudo, foi considerado, ao final da abordagem "regime" no questionário BMQ, a questão complementar: "Algum motivo já levou à interrupção da terapia medicamentosa?" Essa pergunta foi utilizada para marcar o escore em relação à interrupção da terapia devido a atrasos na dispensação do medicamento ou outro motivo, que ocorreram em períodos superiores à última semana. A mesma estratégia, de obter uma complementação da informação, foi utilizada em estudo anterior (Patel et al., 2010) de avaliação da adesão a tratamento anti-hipertensivo utilizando TMG e BMQ. O escore de problemas pontuados pelo BMQ em cada domínio foi obtido a partir da comparação das respostas dos pacientes com a prescrição recebida, registrada em prontuário eletrônico. 
A aplicação dos questionários e complementos de relatos espontâneos dos cuidadores permitiram obter os principais fatores associados à não adesão à terapia medicamentosa com ácido fólico, os quais foram classificados em: dificuldade de acesso ao medicamento (falta no posto de saúde, falta na drogaria, custo elevado); subutilização (falha de dias ou doses; subdoses); resistência por parte da criança em utilizar o medicamento (não gosta do sabor, dificuldade para engolir comprimido, reclamação por polifarmácia); necessidade de interrupção ou atraso da farmacoterapia; histórico de faltas do paciente às consultas no período do estudo; relato de reação adversa; dificuldade em lembrar de administrar o medicamento; e dificuldades referentes à apresentação comercial (abertura/fechamento da embalagem, compreensão das informações em bulário ou embalagem secundária).

A partir do prontuário eletrônico do paciente, obteve-se informações quanto aos registros do diagnóstico da hemoglobinopatia (SS ou SC); resultados laboratoriais dos níveis séricos de ácido fólico; evolução clínica de médico hematologista; e perfil epidemiológico e social das crianças com DF; este último complementado com informações diretas do cuidador, no decorrer da aplicação dos questionários, compreendendo: gênero, idade, procedência, cor da pele referida pelo cuidador, renda familiar e escolaridade materna.

O ácido fólico foi quantitativamente determinado no soro humano através de imunoensaio de Quimioluminescência com partículas paramagnéticas, utilizando o kit “Access ${ }^{\circledR}$ Folate” e o equipamento Beckamn Coulter Unicel DXI 800 (Beckman Coulter Inc., 2005), sendo as amostras colhidas de indivíduos em jejum. Para os resultados de exames que assumiram valores acima do limite de detecção do método (ácido fólico $>25,8 \mathrm{ng} / \mathrm{ml}$ ), realizaram-se as diluições das amostras a fim de se determinar a concentração do analito, de forma a obter resultados mais exatos (Beckman Coulter Inc., 2005).

Análise descritiva exploratória das variáveis envolvidas no estudo e análise bivariada foram realizadas. Para a análise estatística bivariada, categorizou-se a adesão TMG e BMQ em "aderentes" e "não aderentes", sendo considerados “aderentes", aqueles com adesão máxima, ou seja, os pacientes que pontuaram nas 4 questões do Morisky-Green e os que não pontuaram em nenhum domínio do Brief Medication Questionnaire. As demais classificações de adesão terapêutica, foram reclassificadas como "não aderentes". Foram considerados adequados os níveis de ácido fólico séricos compreendidos entre 5,9 e 25,8 ng/ml (Beckman Coulter Inc., 2005). A análise estatística foi realizada com o programa Stata® versão 13.1 e o GraphPad Prism versão 8.0, aplicando-se os testes qui-quadrado e exato de Fisher, para comparações entre variáveis categóricas, e o teste não paramétrico de Mann-Whitney para comparar os valores do ácido fólico segundo o tipo de hemoglobinopatia, forma farmacêutica e adesão (TMG e BMQ), com critério de significância estatística de p<0,05.

O estudo foi aprovado pelo Comitê de Ética e Pesquisa do Hospital Universitário Professor Edgard Santos - UFBA (parecer $\mathrm{n}^{\circ}$ 3.186.618, em 08/03/2019). Todas as crianças participantes foram incluídas após prévia autorização dos pais ou responsável legal e assinatura do TCLE; às maiores de 6 anos, foi aplicado, ainda, o TALE.

\section{Resultados}

Foram identificadas 47 crianças com doença falciforme em uso de terapia profilática com ácido fólico, no período do estudo. Quanto ao perfil epidemiológico e social, os pacientes foram na maioria do sexo masculino (57,5\%), pardos (59,6\%), tinham diagnóstico de hemoglobinopatia SS (61,7\%), faixa etária pré-escolar (70,2\%), procedentes do interior da Bahia $(83,0 \%)$. Apresentaram média (DP) de idade de 4,4 (2,2) anos, mediana (p25-p75) de 4,0 (3,0 - 6,0) anos, variando de 2,0 a 11,0 anos (Tabela 1). 
Tabela 1 - Caracterização sociodemográfica de crianças com Doença Falciforme atendidas pelo Serviço de Referência em Triagem Neonatal (SRTN) da Bahia.

\begin{tabular}{|c|c|c|}
\hline Variável & $\mathbf{n}$ & $\%$ \\
\hline \multicolumn{3}{|l|}{ Sexo } \\
\hline Feminino & 20 & 42,5 \\
\hline Masculino & 27 & 57,5 \\
\hline \multicolumn{3}{|l|}{ Cor da pele referida pelo cuidador } \\
\hline Amarelo & - & - \\
\hline Branco & 4 & 8,5 \\
\hline Indígena & 1 & 2,1 \\
\hline Pardo & 28 & 59,6 \\
\hline Negro & 10 & 21,3 \\
\hline Não declararam ou dados ausentes & 4 & 8,5 \\
\hline \multicolumn{3}{|l|}{ Hemoglobinopatia } \\
\hline $\mathrm{HbSS}$ & 29 & 61,7 \\
\hline $\mathrm{HbSC}$ & 18 & 38,3 \\
\hline \multicolumn{3}{|l|}{ Faixa etária } \\
\hline Pré-escolar (2 a 4 anos) & 33 & 70,2 \\
\hline Escolar (5 a 9 anos) & 11 & 23,4 \\
\hline Adolescente (10 a 19 anos) & 3 & 6,4 \\
\hline \multicolumn{3}{|l|}{ Procedência } \\
\hline Salvador e Região Metropolitana & 8 & 17,0 \\
\hline Interior do estado & 39 & 83,0 \\
\hline \multicolumn{3}{|l|}{ Escolaridade Materna } \\
\hline Até Fundamental Completo & 20 & 42,5 \\
\hline Ensino Médio em diante & 25 & 53,2 \\
\hline Não declararam ou dados ausentes & 2 & 4,3 \\
\hline \multicolumn{3}{|l|}{ Renda Familiar } \\
\hline Menos de 1 salário mínimo & 20 & 42,5 \\
\hline De 1 a menos que 2 salários mínimos & 23 & 48,9 \\
\hline Maior ou igual a 2 salários mínimos & 2 & 4,3 \\
\hline Não declararam ou dados ausentes & 2 & 4,3 \\
\hline
\end{tabular}

Fonte: Autores.

Predominaram prescrições de ácido fólico em comprimidos com posologia de $5 \mathrm{mg}$, uma vez ao dia, todos os dias da semana; seguido dos esquemas posológicos: 1/2 (meio) comprimido de $5 \mathrm{mg}$, uma vez ao dia, todos os dias da semana e, solução oral $0,2 \mathrm{mg} / \mathrm{ml}, 20$ gotas, diário (Tabela 2). No estudo, observou-se, a partir da aplicação dos questionários, casos de divergências $(29,3 \% ; 12 / 41)$ entre o que foi prescrito pelo hematologista e o que era utilizado pelas crianças.

A adesão terapêutica ao ácido fólico foi "máxima" em 34,1\% e 40,4\% dos pacientes, segundo o TMG e BMQ, respectivamente. A principal barreira apontada para os casos de não adesão foi a de regime terapêutico $(51,0 \%)$, em relação a falhas de dias e doses de tratamento, seguido do domínio recordação $(34,0 \%)$, relacionado à lembrança em utilizar os medicamentos (Tabela 2).

Quanto aos níveis séricos de ácido fólico, nenhum paciente apresentou valores abaixo da normalidade. Entretanto, houve predomínio de resultados elevados, acima do limite superior de normalidade $(78,7 \%$; 37/47). 
Tabela 2 - Esquemas terapêuticos, adesão pelos métodos TMG e BMQ, níveis séricos de ácido fólico categorizados das crianças atendidas pelo Serviço de Referência em Triagem Neonatal da Bahia.

\begin{tabular}{|c|c|c|}
\hline Variável & $\mathbf{n}$ & $\%$ \\
\hline \multicolumn{3}{|l|}{ Esquema terapêutico } \\
\hline $\mathrm{AF}^{\mathrm{a}} 5 \mathrm{mg}(1 \mathrm{comp}, 1 \mathrm{x} / \mathrm{dia})$ & 18 & 38,3 \\
\hline AF $5 m g(1 / 2$ comp, $1 x /$ dia $)$ & 13 & 27,7 \\
\hline AF $0,2 \mathrm{mg}(10$ gotas, $1 \mathrm{x} / \mathrm{dia})$ & 3 & 6,3 \\
\hline AF $0,2 \mathrm{mg}$ (20gotas, $1 \mathrm{x} / \mathrm{dia})$ & 13 & 27,7 \\
\hline \multicolumn{3}{|l|}{ Adesão - TMG ${ }^{b}$} \\
\hline Baixa Adesão & 2 & 4,3 \\
\hline Moderada Adesão & 29 & 61,7 \\
\hline Aderente (adesão máxima) & 16 & 34,0 \\
\hline \multicolumn{3}{|l|}{ Adesão - BMQ ${ }^{c}$} \\
\hline Baixa Adesão & 3 & 6,4 \\
\hline Provável Baixa Adesão & 10 & 21,3 \\
\hline Provável Aderência & 15 & 31,9 \\
\hline Aderente (adesão máxima) & 19 & 40,4 \\
\hline \multicolumn{3}{|l|}{ Escore BMQ } \\
\hline \multicolumn{3}{|l|}{ Regime (escore) } \\
\hline 0 & 23 & 49,0 \\
\hline$\geq 1$ & 24 & 51,0 \\
\hline \multicolumn{3}{|l|}{ Crenças (escore) } \\
\hline 0 & 42 & 89,4 \\
\hline$\geq 1$ & 5 & 10,6 \\
\hline \multicolumn{3}{|l|}{ Recordação (escore) } \\
\hline 0 & 31 & 66,0 \\
\hline$\geq 1$ & 16 & 34,0 \\
\hline \multicolumn{3}{|l|}{ Níveis séricos de AF categorizados } \\
\hline Níveis séricos adequados $(5,9-25,8 \mathrm{ng} / \mathrm{ml})$ & 10 & 21,3 \\
\hline Níveis séricos elevados especificados (> 25,8ng/ml) & 37 & 78,7 \\
\hline
\end{tabular}

a) AF:Ácido Fólico; b) TMG: Teste de Morisky-Green; c) BMQ: Brief Medication Questionnaire. Fonte: Autores.

Os principais fatores relacionados à não adesão ao ácido fólico, obtidos por relato espontâneo dos cuidadores, foram dificuldade de acesso ao medicamento (59,6\%), e interrupção/atraso no tratamento (49,0\%), decorrentes principalmente pela falta do medicamento no posto de saúde, mudança na rotina (viagem, partilha na responsabilidade da administração do medicamento, quando no caso de guarda compartilhada da criança). Dificuldades referentes a apresentação comercial (46,8\%) e resistência da criança (42,5\%) também estiveram presentes em quase metade da população monitorada, com destaques para dificuldades quanto a leitura e entendimento do bulário e de dados da embalagem secundária, e quanto à deglutição do comprimido pelo paciente (Gráfico 1).

Gráfico 1 - Percentual dos Principais motivos para não adesão a farmacoterapia ao ácido fólico, segundo BMQ. 


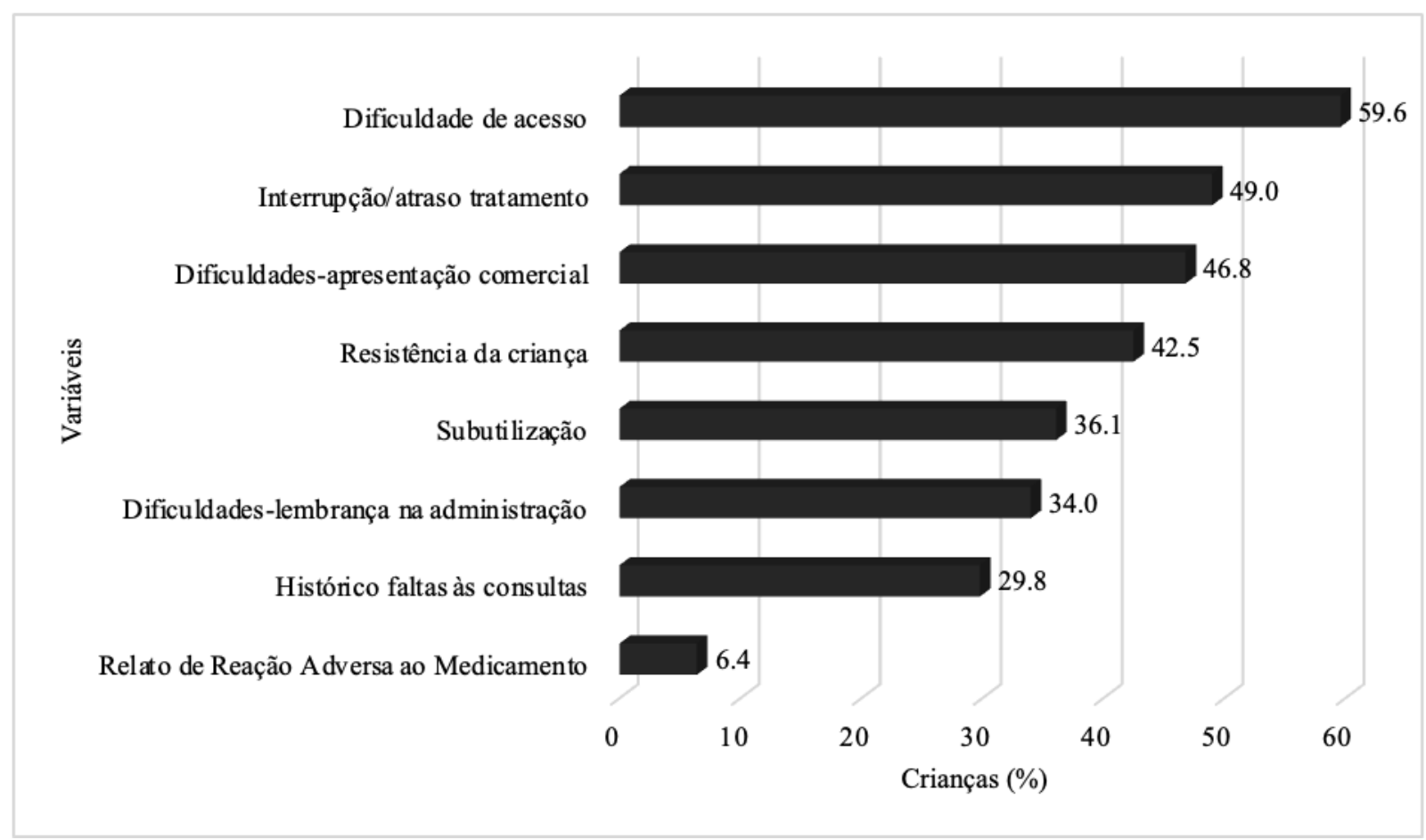

Fonte: Autores.

A forma farmacêutica $(p=0,719)$, faixa etária $(p=0,875)$, escolaridade do cuidador $(p=0,070)$ e renda familiar ( $\mathrm{p}=0$,944) não foram associados a maior adesão, considerando o questionário TMG. Resultados similares foram observados para o questionário $\mathrm{BMQ}$, para a forma farmacêutica $(\mathrm{p}=0,112)$, faixa etária $(\mathrm{p}=0,825)$, escolaridade do cuidador $(\mathrm{p}=0,345)$ e renda familiar $(\mathrm{p}=0,736)$. Contudo, observou-se que pacientes com hemoglobinopatia SS registraram mais que o quádruplo de adesão comparado aos de hemoglobinopatia SC (48,3\% vs. 11,1\%; p=0,012), segundo análise por TMG (Tabela 3).

Os níveis séricos de ácido fólico foram similares entre os tipos de hemoglobinopatia, segundo a forma farmacêutica (Figura 1A) e a classificação da adesão referida por questionários (Figura 1B).

Tabela 3 - Análise univariada entre as variáveis do estudo e o perfil de adesão, segundo TMG e BMQ, das crianças atendidas pelo Serviço de Referência em Triagem Neonatal da Bahia.

\begin{tabular}{|c|c|c|c|c|c|c|c|c|}
\hline \multirow{3}{*}{ Variável } & \multirow{2}{*}{\multicolumn{2}{|c|}{ Total }} & \multirow{2}{*}{\multicolumn{2}{|c|}{$\begin{array}{c}\text { TMG } \\
\text { Aderente } \\
\end{array}$}} & \multirow{3}{*}{$\mathbf{p}$} & \multirow{2}{*}{\multicolumn{2}{|c|}{$\begin{array}{c}\text { BMQ } \\
\text { Aderente }\end{array}$}} & \multirow{3}{*}{$\mathbf{p}$} \\
\hline & & & & & & & & \\
\hline & $\mathrm{N}$ & $\%$ & $\mathrm{~N}$ & $\%$ & & $\mathrm{~N}$ & $\%$ & \\
\hline Forma Farmacêutica & & & & & 0,719 & & & 0,112 \\
\hline Comprimidos & 31 & 66,0 & 10 & 32,3 & & 10 & 32,3 & \\
\hline Gotas & 16 & 34,0 & 6 & 37,5 & & 9 & 56,2 & \\
\hline Faixa etária & & & & & 0,875 & & & 0,825 \\
\hline 2-4 anos & 33 & 70,2 & 11 & 33,3 & & 13 & 39,4 & \\
\hline$>4$ anos & 14 & 29,8 & 5 & 35,7 & & 6 & 42,9 & \\
\hline Escolaridade do cuidador* & & & & & 0,07 & & & 0,345 \\
\hline Até Fundamental Completo & 20 & 44,4 & 10 & 50,0 & & 10 & 50,0 & \\
\hline A partir do Ensino Médio & 25 & 55,6 & 6 & 24,0 & & 9 & 36,0 & \\
\hline
\end{tabular}


Renda Familiar*

\section{$\geq 1 \mathrm{SM}$}

$<1 \mathrm{SM}$

$25 \quad 55,6$

$20 \quad 44,4$

Hemoglobinopatia

SS

$\mathrm{SC}$

$\begin{array}{llcc}29 & 61,7 & 14 & 48,3 \\ 18 & 38,3 & 2 & 11,1\end{array}$

0,944

36,0

35,0

48,3

1,1
0,012

0,23
0,736

40,0

45,0

$\begin{array}{cl}10 & 45,0\end{array}$

0,435

44,9

33,3

$\begin{array}{cc}13 & 44,9 \\ 6 & 33,3\end{array}$

Níveis séricos de ácido fólico

50,0

0,487

Adequados

$10 \quad 21,3$

5

29,7

$\begin{array}{cc}5 & 50 \\ 14 & 37,8\end{array}$

Elevados

$37 \quad 78,7$

11

37,8

TMG: Teste de Morisky Green; BMQ: Brief Medication Questionnaire; SM: Salário Mínimo *Os totais não coincidem devido à falta de dados de determinados participantes no estudo. Fonte: Autores.

Figura 1 - Distribuição dos valores de ácido fólico (em $\mathrm{ng} / \mathrm{ml}$ ) segundo forma farmacêutica, tipo de hemoglobinonopatia e adesão (TMG e BMQ).
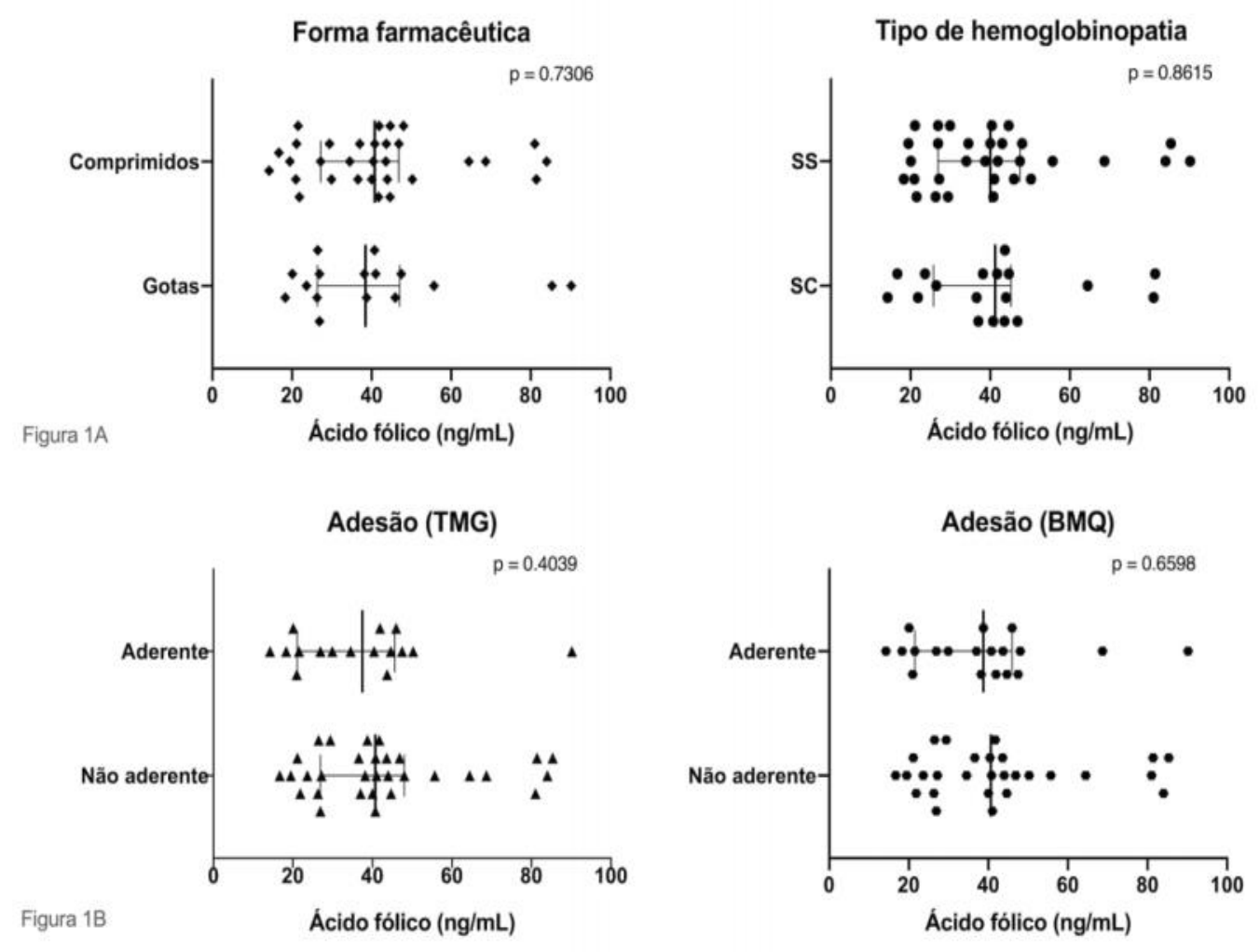

Dados representados segundo tipo de hemoglobinopatia (1A), forma farmacêutica (1A) e adesão por questionários TMG e BMQ (1B). As barras verticais nos gráficos correspondem à mediana e o intervalo interquartil dos dados. Fonte: Autores

\section{Discussão}

Os resultados encontrados demonstraram que a maioria dos pacientes apresentou adesão "moderada" e "provável adesão" para o TMG e BMQ, respectivamente, o que está relacionado com falhas na adesão em pelo menos um dos itens questionados. Os principais fatores que contribuíram para a não adesão foram dificuldade de acesso ao medicamento, principalmente devido ao constante desabastecimento nas unidades de saúde, relatado pelos cuidadores, e mudanças nas rotinas das crianças. Apesar disso, os níveis séricos de ácido fólico observados foram excessivos em $75 \%$ das crianças avaliadas e 
nenhuma delas apresentava deficiência.

Poucos estudos avaliaram a adesão ao ácido fólico em crianças com DF, especialmente comparando métodos indiretos, como questionários ou registros de dispensação, com a dosagem do metabólito em fluidos biológicos. Patel et. al. (2010) mostraram que a adesão média ao ácido fólico, em coorte prospectiva de crianças com doença falciforme, foi de $60 \%$ em um ano de seguimento. Nesse trabalho, foi utilizado como parâmetro para medir a aderência, a razão entre o número de dias esperados entre os períodos de recarga e os dias observados entre os períodos de recarga para medicamentos de uso diário. No entanto, os autores referem que a adesão pode ter assumido valores menores, uma vez que a dispensação do medicamento não necessariamente corresponde ao uso deste pelo paciente ou seu uso na dose e intervalo de tempo adequados.

Múltiplos foram os fatores que contribuíram para não adesão ao ácido fólico. No presente estudo, o domínio mais pontuado para a não adesão, segundo BMQ, foi o de Regime Terapêutico, em relação a falhas de dias e doses do tratamento, seguido de Recordação. Problemas relacionados a adesão terapêutica são principalmente observados nos casos de tratamento de doenças crônicas, no qual o paciente necessita utilizar o medicamento por um período maior de tempo, podendo inclusive interrompê-lo quando assintomático (Steiner et al., 2013). No estudo, não foram observados casos de suspensão do AF quando a criança se encontrava estável. Outra característica da amostra estudada, corresponde a complexidade do regime terapêutico, fator apontado, em estudos prévios, como interferente nas taxas de adesão ao tratamento medicamentoso (Bugni et al., 2012; Walsh et al., 2014). Bugni et. al. (2012) observaram, em crianças com doenças reumatológicas, que a utilização diária de mais de três medicamentos diferentes foi indicadora de má adesão. As crianças com doença falciforme atendidas ambulatorialmente, realizam em média uso de três medicamentos/dia (Patel et al., 2010; Walsh et al., 2014).

Dificuldade de acesso foi o fator associado a não adesão mais referido entre os cuidadores das crianças estudadas. A dificuldade de acesso foi igualmente observada em estudo transversal com adultos em uso contínuo de medicamentos, que demonstrou que a falta de recursos financeiros para a aquisição dos medicamentos e não ter conseguido obtê-los nos serviços de saúde representa importante impacto para a continuidade efetiva da terapia farmacológica (Remondi, Cabrera, \& Souza, 2014). De fato, o desabastecimento tem sido referido como importante fator que contribui para a não adesão, com necessidades de interrupção do tratamento; sendo apontado como principal barreira de acesso no Brasil (Nascimento et al., 2017). Segundo avaliação da assistência farmacêutica no Brasil, a média anual nacional de indisponibilidade de medicamentos essenciais é de 25\%; sendo o tempo médio de desabastecimento de 84 dias/ ano (Brasil, 2005).

O ácido fólico constitui um Componente Básico da Assistência, fazendo parte da Relação Nacional de Medicamentos Essenciais (RENAME) sob apresentação comprimido $5 \mathrm{mg}$ e gotas $0,2 \mathrm{mg} / \mathrm{ml}$. Embora não exista um consenso nacional, preconiza-se a reposição de 1 a $5 \mathrm{mg} /$ dia de ácido fólico (Brasil, 2012) e, mais recentemente, o uso de $5 \mathrm{mg}$ três vezes/semana em pacientes em uso de hidroxiuréia (Brasil, 2016). O uso de comprimidos como forma farmacêutica na faixa etária pediátrica torna a precisão da posologia mais difícil (Steiner et al., 2013). Apesar disso, no presente estudo não foram observadas diferenças significantes na adesão referida entre as formas farmacêuticas. Contudo, alguns cuidadores relataram dificuldades de acesso a forma farmacêutica prescrita (comprimido ou gotas), outros demonstraram não compreensão da posologia presente na receita médica e, dessa forma, realizaram substituições por conta própria; implicando em falhas de dias e doses do fármaco. Isso foi confirmado com um percentual de quase 30\% de divergência entre o prescrito pelo médico hematologista e o realmente efetivado referido pelo cuidador. A prescrição do ácido fólico na instituição é realizada conforme peso e idade dos pacientes, tendo modificações do regime terapêutico ao longo do acompanhamento da criança. Essa condição foi referida como importante barreira a adesão nos pacientes acompanhados. Não se tem conhecimento sobre o impacto a longo prazo na saúde das crianças pela utilização do ácido fólico contínuo em posologia divergente à prescrita. No estudo, as crianças que utilizavam o ácido fólico de forma distinta à recomendada pelo hematologista tendiam a tomar dose menor que a necessária (12,76\%), sendo essa condição pouco provável para a elevação dos níveis de folato sérico. Estudos de monitoramento e de avaliação da 
segurança de doses prescritas do ácido fólico na população pediátrica, bem como seus efeitos sobre os níveis séricos de folato e impactos sobre o quadro da anemia hemolítica crônica são insuficientes (Azzam \& Attalla, 2019).

Outros aspectos relacionados à rotina de acompanhamento destas crianças foram relatados como relacionados à não adesão. Modificações em rotina, por conta de viagem para a realização de consultas, responsabilidade compartilhada para administração do medicamento, foram fatores que igualmente interferiram na adesão, tal como descrito em revisão sistemática (Walsh et al., 2014). A adesão terapêutica é facilitada quando os tratamentos farmacológicos são mais simples, de curta duração e quando o processo de sua utilização interfere pouco em rotinas habituais. A necessidade de administração do medicamento por um cuidador, igualmente torna o processo de adesão em crianças mais complexo, sendo necessário considerar aspectos como o responsável estar ou não doente, ser ou não pai/mãe da criança (Liberato et al., 2014).

Quanto a possíveis relações do perfil epidemiológico e social dos participantes com a adesão, faixa etária da criança, renda e escolaridade do cuidador não demonstraram associação com a adesão ao fármaco, semelhante ao encontrado em acompanhamento de pacientes pediátricos com condição crônica de saúde e em uso contínuo de medicamentos em outro estudo (Adriano et al., 2017). A forma farmacêutica também não interferiu nas taxas de adesão ao ácido fólico. Esta observação sugere que a aderência seja mais específica do paciente do que específica do fármaco, tal como apontam trabalhos anteriores (Patel et al., 2010; Bugni et al., 2012; Adriano et al., 2017;). Contudo, um achado deste trabalho foi relevante: pacientes com a condição mais grave da doença (SS) apresentaram adesão mais de quatro vezes superior aos SC, quando aferidos pelo TMG. De fato, é sabido que a gravidade da doença ou ausência de sintomas apresentam importante impacto na adesão (Obreli-Neto et al., 2012; Steiner et al., 2013). Apesar desse achado significante, os níveis séricos de ácido fólico não diferiram de acordo com o tipo de hemoglobinopatia.

A elevada porcentagem de pacientes "não aderentes" à farmacoterapia com ácido fólico contrastou com o achado de que a maior parte das crianças monitoradas apresentaram níveis de ácido fólico sérico elevados. Ademais, não houve diferença significativa nos níveis séricos de ácido fólico daqueles classificados como "aderentes" e "não aderentes". Algumas hipóteses podem ser elencadas para este achado. Primeiramente, a ocorrência dessa condição pode ser explicada pela possibilidade de suplementação através de outras fontes não medicamentosas, tal como ingestão de alimentos enriquecidos (farinhas de trigo, milho, arroz) (Brasil, 2009; Vaish et al., 2016). Não foi objetivo do estudo averiguar questões relacionadas à dieta, porém pesquisadores apontam elevado consumo de biscoitos, massas, cereais e derivados por crianças nessa faixa etária (Leal et al., 2015; Alves et al., 2019).

Outra possibilidade explicativa diz respeito à prescrição de doses excessivas que podem manter níveis séricos elevados, mesmo com o uso irregular do medicamento em casos não aderentes. Achados de níveis séricos elevados em 78,7\% das crianças, quando somente 37,8\% deles eram aderentes aos questionários, podem indicar essa possibilidade. Uma terceira hipótese pode estar representada por uma possível falta de eficácia da suplementação de ácido fólico nestas crianças. Dois estudos recentes sugerem essa possibilidade. Uma recente revisão encontrou apenas um estudo duplo cego, controlado por placebo, no qual se relatou níveis mais altos de AF no grupo suplementado, mas nenhuma diferença nas medidas de hemoglobina entre os grupos suplementado e placebo (Dixit et al., 2018). Adicionalmente, Nguyen et al. (2017) em um estudo de coorte de pacientes jovens de 1 a 24 anos com anemia falciforme (SS) que pararam de tomar o ácido fólico, não encontraram nenhum efeito da suplementação de AF sobre o status de folato ou síntese de hemácias. Embora anemias hemolíticas, como a causada pela doença falciforme, possam resultar em folatopenia, menores necessidades dessa vitamina do que as ingeridas poderiam explicar a menor metabolização do ácido fólico e seu excesso sérico.

As limitações do presente estudo incluem o desenho transversal, que não permitiu a avaliação da adesão ao longo do tempo e o tamanho amostral que limitou a capacidade de investigar as interações entre as variáveis do estudo por meio de análise multivariada. Além disso, a investigação da dieta é um aspecto importante para avaliação, já que os níveis de folato 
sérico variam significativamente com a dieta, independente da técnica de dosagem laboratorial, sérica ou eritrocitária, esta última um melhor indicador da reserva de ácido fólico que a concentração sérica do folato (Vaish et al., 2016).

Observou-se um considerável número de crianças com falhas na adesão à terapia profilática com ácido fólico, bem como discordância entre a adesão referida pelos questionários e dosagem sérica de folato. Nesse sentido, faz-se necessário considerar estratégias para o fortalecimento da adesão a farmacoterapia; e a necessidade de reavaliação do esquema posológico desse medicamento para o grupo pediátrico, de forma a adequá-lo à condição clínica dos mesmos, considerando a necessidade de suplementação, impactos futuros à saúde e fatores relacionados à custo-efetividade.

\section{Conclusão}

Os resultados do estudo sugerem contraste entre a adesão a terapia com ácido fólico referida pelos questionários e os elevados níveis séricos de folato nas crianças com doença falciforme acompanhadas, bem como a necessidade de melhoria do acesso ao medicamento. Ações com foco em educação em saúde e reforço da necessidade do seu uso racional são imprescindíveis junto aos cuidadores.

Praticamente todas as crianças em seguimento tiveram níveis de ácido fólico elevados, sugerindo a necessidade monitoramento dos níveis de ácido fólico a partir de resultados de exames e observação da dieta, vez que os mesmos apresentaram valores muito acima do limite de referência, não se tendo uma resposta concreta do impacto dessa elevação na saúde das crianças em uso contínuo. Adicionalmente, as doses preconizadas de suplementação do ácido fólico devem ser revisadas, bem como medidas para reduzir a interrupção do fornecimento do medicamento durante o seu uso. Estudos futuros devem considerar essas limitações em seu desenho para responder questões surgidas após o presente trabalho. Especificamente, estudos de eficácia da suplementação do ácido fólico nestes pacientes devem ser realizados.

\section{Referências}

Adriano L.S., Fonteles M.M.F., Azevedo M.F.M., Beserra M.P.P., Romero N.R. (2017). Medication adherence in patients with juvenile idiopathic arthritis. Rev Bras Reumatol., 57(1):23-29.

Alves M.A., Souza A.M., Barufaldi L.A., Tavares B.M., Bloch K.V., Vasconcelos F.A.G. (2019). Dietary patterns of Brazilian adolescents according to geographic region: an analysis of the Study of Cardiovascular Risk in Adolescents (ERICA). Cad Saude Publica, $35(6): \mathrm{e} 00153818$.

Amorim T., Pimentel H., Fontes M.I.M.M., Purificação A., Lessa P., Boa-Sorte N. (2010). Avaliação do programa de triagem neonatal da Bahia entre 2007 e 2009 - As lições da doença falciforme. Gaz. méd. Bahia, 80(3):10-13.

Azzam M. \& Attalla S. (2019). Serum Folate Levels in Patients with Chronic Hemolytic Anemia on Regular Folic Acid Supplementation Before and After Dose Modification. Indian Pediatr., 56(10):845-848.

Bandeira F.M.G.C., Bezerra M.A.C., Santos M.N.N., Gomes Y.M., Araújo A.S., Abath F.G.C. (2007). Importância dos programas de triagem para o gene da hemoglobina S. Rev Bras Hematol Hemoter., 29(2):179-84.

Ben A.J. (2011). Confiabilidade e Análise de Desempenho de Dois Questionários de Avaliação da Adesão ao Tratamento Anti-hipertensivo: Teste de Morisky-Green e Brief Medication Questionnaire [dissertação]. Porto Alegre (RS): Universidade Federal do Rio Grande do Sul; 2011.

Ben A.J., Neumann C.R., Mengue S.S. (2012). The Brief Medication Questionnaire and Morisky-Green test to evaluate medication adherence. Rev Saude Publica, 46(2):279-289.

Beckman Coulter Inc. Access® Immunoassay Systems - $\quad$ Folate. $2005 . \quad$ [acessado 2019 jun 09]. http://www.biosystemsne.com.br/files/product/4b3390f9ec51a.511a14208.pdf.

Bitarães E.L., Oliveira B.M., Viana M.B. (2008). Adesão à antibioticoterapia profilática em crianças com anemia falciforme: um estudo prospectivo. $J$ Pediatr,84(4):316-22.

Braga J.A.P. (2007). Medidas gerais no tratamento das doenças falciformes. Rev Bras Hematol Hemoter., 29(3):233-8.

Brasil. (2005). Organização Pan Americana da Saúde (OPAS). Avaliação da assistência farmacêutica no Brasil: estrutura, processo e resultados. Brasília: OPAS.

Brasil. (2009). Portaria N $\mathrm{N}^{\mathrm{o}}$ 1.793, de 11 de agosto de 2009. Institui a Comissão Interinstitucional para Implementação, Acompanhamento e Monitoramento das Ações de Fortificação das Farinhas de Trigo, de Milho e de seus Subprodutos. Diário Oficial da União $2009 ; 11$ ago. 
Brasil. (2012). Ministério da Saúde (MS). Doença falciforme: condutas básicas para tratamento. Brasília: Ministério da Saúde.

Brasil. (2016). Ministério da Saúde (MS). CONITEC - Comissão Nacional de Incorporação de Tecnologias em Saúde. Protocolo Clínico e Diretrizes Terapêuticas de Doença Falciforme. Brasília: Ministério da Saúde.

Bugni V.M., Ozaki L.S., Okamoto K.Y., Barbosa C.M., Hilário M.O., Len C.A., Terreri M.A. (2012). Factors associated with adherence to treatment in children and adolescents with chronic rheumatic diseases. J Pediatr (Rio J), 88(6):483-8.

Caldas P., Boa-Sorte N., Amorim T., Freitas M., Ribeiro R., Fonseca SFd. (2010). Eventos Clínicos e Fatores Associados em uma coorte de crianças com Doença Falciforme. Gaz. méd. Bahia, 80(3):14-19.

Cançado R.D. \& Jesus J.A. (2007). A doença falciforme no Brasil. Rev Bras Hematol Hemoter., 29(3):204-206.

Dixit R., Nettem S., Madan S.S., Soe H.H.K., Abas A.B., Vance L.D., Stover P.J (2018). Folate supplementation in people with sickle cell disease. Cochrane Database Syst Rev.,3(3):CD011130.

Leal K.K., Schneider B.C., França G.V., Gigante D.P., dos Santos I., Assunção M.C. (2015). Diet quality of preschool children aged 2 to 5 years living in the urban area of Pelotas, Brazil. Rev Paul Pediatr., 33(3):311-318.

Liberato S.M.D., Souza A.J.G., Gomes A.T.L., Medeiros L.P., Costa I.K.F., Torres G.V. (2014). Relação entre adesão ao tratamento e qualidade de vida: revisão integrativa da literatura. Rev Eletr Enferm.,16(1):191-198.

Nascimento R.C.R.M., Álvares J., Guerra A.A., Gomes I.C., Costa E.A., Leite S.N., Costa K.S., Soeiro O.M., Guibu I.A., Karnikowski M.G.O., Acurcio F.A. (2017) Availability of essential medicines in primary health care of the Brazilian Unified Health System. Rev Saude Publica, 51(2):10s.

Nguyen G.T., Lewis A., Goldener C., Reed B., Dulman R.Y., Yang E. (2017). Discontinuation of Folic Acid Supplementation in Young Patients With Sickle Cell. Anemia. J Pediatr Hematol Oncol.,39(6):470-472.

Obreli-Neto P.R., Baldoni A.O.B., Guidoni C.M., Bergamini D., Hernandes K.C., da Luz R.T, da Silva F.B., de Oliveira e Silva R., Pereira L.R.L., Cuman R.K.N. (2012). Métodos de avaliação de adesão à farmacoterapia. Rev Bras Farm, 93(4):403-410.

Patel N.G., Lindsey T., Strunk R.C., DeBaun M.R. (2010). Prevalence of daily medication adherence among children with sickle cell disease: a 1-year retrospective cohort analysis. Pediatr Blood Cancer, 55(3):554-556.

Piel F.B., Patil A.P., Howes R.E., Nyangiri O.A., Gething P.W., Dewi M., Temperley W.H., Williams T.N., Weatherall D.J., Hay S.I. (2013). Global epidemiology of sickle haemoglobin in neonates: a contemporary geostatistical model-based map and population estimates. Lancet, $381(9861): 142-51$.

Remondi F.A., Cabrera M.A., Souza R.K. (2014). Non-adherence to continuous treatment and associated factors: prevalence and determinants in adults 40 years and older. Cad Saude Publica, 30(1):126-136.

Steiner S.A., Torres M.R.F., Penna F.J., Melo M.C.B. (2013) Adesão ao tratamento de doenças crônicas em pediatria: uma revisão crítica da literatura. Rev Med Minas Gerais, 23(2):5-11.

Vaish S., White M., Daly L., Molloy A.M., Staines A., Sweeney M.R. (2016). Synthetic folic acid intakes and status in children living in Ireland exposed to voluntary fortification. Am J Clin Nutr., 103(2):512-518.

Walsh K.E., Cutrona S.L., Kavanagh P.L., Crosby L.E., Malone C., Lobner K., Bundy D.G. (2014). Medication adherence among pediatric patients with sickle cell disease: a systematic review. Pediatrics, 134(6):1175-1183.

Ware R.E., de Montalembert M., Tshilolo L., Abboud M.R. (2017). Sickle cell disease. Lancet, 390 (10091):311-323. 